\title{
(-)-Epigallocatechingallate Interferes RANKL/RANK Signal Pathway and Induces Apoptosis during Osteoclastogenesis in RAW264 Cell
}

\author{
Ran Zhao $^{1}$, Masayoshi Kamon ${ }^{1,2}$, Kazuichi Sakamoto ${ }^{1 *}$ \\ ${ }^{1}$ Graduate School of Life and Environmental Sciences, University of Tsukuba, Tsukuba, Japan, ${ }^{2}$ Center for Genomic Medicine, The \\ Saitama Medical Research University, Hidakashi, Japan. \\ Email: "sakamoto@biol.tsukuba.ac.jp
}

Received September $3^{\text {rd }}$, 2013; revised October $3^{\text {rd }}$, 2013; accepted October $10^{\text {th }}, 2013$

Copyright (C) 2014 Ran Zhao et al. This is an open access article distributed under the Creative Commons Attribution License, which permits unrestricted use, distribution, and reproduction in any medium, provided the original work is properly cited. In accordance of the Creative Commons Attribution License all Copyrights (C) 2014 are reserved for SCIRP and the owner of the intellectual property Ran Zhao et al. All Copyright (C) 2014 are guarded by law and by SCIRP as a guardian.

\section{ABSTRACT}

Green tea catechin, (-)-epigallocatechin-3-gallate [(-)-EGCG], was found to increase osteogenic functioning in mesenchymal stem cells. This study qualified EGCG, the strongest inhibitory efficiency for receptor activator of nuclear factor- $\kappa$ B (NF- $\kappa$ B) ligand (RANKL)-activated osteoclastogenesis among other green tea catechins for RAW264, a murine preosteoclast cell line. Moreover, EGCG inhibited tartrate-resistant acid phosphatase (TRAP)-positive multinucleated cell formation dose dependently in both single culture and co-culture systems, the expression of transcription factor, nuclear factor of activated T-cells, cytoplasmic 1 (NFATc1) and some osteoclastic genes. Especially, EGCG exhibited a strong inhibitory effect on the expression levels of RANK, the receptor of RANKL, and OSCAR, a key co-stimulator of the RANKL/RANK signal. Simultaneously, apoptotic genes expression and Hoechst staining revealed that EGCG induced apoptosis in RAW264. Taken together, these data suggest that the inhibitory effect of EGCG to osteoclastogenesis is associated with a down regulation of RANKL/RANK signal, and increased apoptosis of preosteoclasts.

\section{KEYWORDS}

\section{(-)-Epigallocatechin-3-Gallate; RANK; Osteoclastogenesis; Apoptosis}

\section{Introduction}

Skeletal degenerative diseases such as osteoporosis have become increasingly prevalent with the increase in the lifespan of human [1]. Regardless of the cause, osteoporosis reflects a relative preponderance of osteoclast activity. Osteoclastogenesis is a complicated process involving many stages such as commitment, differentiation, multinucleation, and activation of immature osteoclasts. A variety of both systemic hormones and cytokines locally produced in the bone microenvironment regulates the differentiation and function of osteoclasts $[2,3]$.

Receptor activator of nuclear factor- $\kappa \mathrm{B}$ ligand (RANKL), physiologically, expressed by stromal cells in the bone marrow and osteoblasts in the periosteum, is a protein

\footnotetext{
${ }^{*}$ Corresponding author.
}

present on the membranes of osteoblasts and their precursors, which activates the receptor RANK, on osteoclast precursors [4]. Targeted disruption of RANK also results in severe osteopetrosis, which suggests that the RANKL/RANK interaction plays an essential role in osteoclast formation in vivo [5]. Nuclear factor of activated T-cells, cytoplasmic 1 (NFATc1) has been reported to be the transcription factor most strongly induced by RANKL, which activates NF- $\kappa$ B and AP-1 [6]. NFATc1 regulates many osteoclast-specific genes such as Cathepsin $\mathrm{K}$, tartrate-resistant acid phosphatase (TRAP), and calcitonin receptor (CtR) [7,8]. Immunoglobulin-like costimulatory molecules associated with $\mathrm{FcR} \gamma$ and DAP12 such as osteoclast-associated receptor (OSCAR) are involved in the activation of calcium signals leading to the induction of NFATc1 [9-11]. 
In mammalian cells, SIRT1 has a dual effect on FOXO3a function: SIRT1 increases the ability of FOX$\mathrm{O} 3$ to induce cell cycle arrest and resistance to oxidative stress but inhibits its ability to induce cell death [12]. Cell death is also regulated by complex interactions between the members of the Bcl-2 family [13]. Among the members of the BCL-2 homology domain 3 (BH3) family, proapoptotic member Bim has been classified as an "activator" in view of its purported ability to directly engage and activate Bax and Bak. Bax and Bak, when engaged, trigger mitochondrial outer membrane permeabilization (MOMP), which results in the release of proapoptoticproteins (e.g., cytochrome c) from the mitochondria to the cytosol, thereby initiating the caspase cascade [14]. In addition, Caspase-3-Bim axis has been reported to play an important role in regulating the apoptosis of osteoclasts [15].

Among the constituents contained in tea leaves, polyphenoliccatechins are thought to contribute to the biological effects of tea. The main polyphenols found in green tea extracts are (-)-epicatechin [(-)-EC], (-)-epigallocatechin [(-)-EGC], (-)-epicatechin-3-gallate [(-)ECG], and (-)-epigallocatechin-3-gallate [(-)-EGCG]. The latter, (-)-EGCG, the most abundant catechin, was found to be the strongest chemopreventive and anticancer agent among the green tea catechins [16].

Although EGCG has been reported to effectively suppress bone resorption by suppressing the osteoclast formation of RAW264 cells in the presence of RANKL [17], the mechanism is not fully understood. This report aims to elucidate whether EGCG inhibits osteoclastogenesis via the inhibition of RANKL signaling and induces the apoptosis of preosteoclasts.

\section{Materials and Methods}

\subsection{Cell Culture}

RAW264 cells (RIKEN Institute of Physical and Chemical Research Cell Bank, Tsukuba, Ibaraki, Japan) were cultured at $37^{\circ} \mathrm{C}$ in $100-\mathrm{mm}$ dishes in Dulbecco's modified Eagle's medium (DMEM) (Sigma-Aldrich, St. Louis, MO, USA) supplemented with 10\% FBS (Sanko Junyaku, Chiyoda, Tokyo, Japan) and 1\% MEM nonessential amino acid solution (NEAA) (Invitrogen, Carlsbad, CA, USA). To induce osteoclast development, RAW264 cells were plated on a 96-well plate at $2 \times 10^{3}$ cells/well and cultured in minimum essential medium alpha ( $\alpha$-MEM) (Invitrogen) (10\% fetal bovine serum (FBS), 1\% NEAA) containing catechin (EGCG, EGC, ECG or EC) (Mitsui Nourin) and $100 \mathrm{ng} / \mathrm{ml}$ RANKL for 5 days.

MC3T3-E1 cells (RIKEN) were spread at $3.2 \times 10^{4}$ cells $/ \mathrm{cm}^{2}$ in $100-\mathrm{mm}$ dishes, and were cultured in $\alpha$ -
MEM containing $50 \mathrm{mg} / \mathrm{l}$ ascorbic acid, supplemented with $10 \%$ FBS (Sanko Junyaku) at $37^{\circ} \mathrm{C}$ for 10 days.

We obtained bone marrow cells from femurs and tibiae of 6-week-old male mouse and osteoblasts from mouse newborn calvaria (Saitama Experimental Animal Supply, Katsushika, Saitama, Japan). Bone marrow cells and osteoblasts were spread in the same plate with $\alpha$-MEM (10\% FBS) at a density of $2 \times 10^{5}$ and $2 \times 10^{4}$ cells/well respectively (co-culture). To stimulate the differentiation of osteoclasts, these cells were cultured simultaneously on the same plate for 6 days under the stimulation of $10^{-8} \mathrm{M} 1,25(\mathrm{OH})_{2} \mathrm{D}_{3}$ (Wako, Chuo, Osaka, Japan) [18].

\subsection{TRAP (Tartrate-Resistant Acid Phsphatase) Staining}

Wells were washed with PBS, and cells were fixed by incubation with $100 \mu \mathrm{l}$ of $4 \%$ paraformaldehyde (Wako) at $4^{\circ} \mathrm{C}$ for $1 \mathrm{~h}$. Each well was washed with distilled water, and then $100 \mu \mathrm{l}$ of tartrate-resistant acid phosphatase (TRAP) solution (50 mM sodium tartrate (KANTO-Kagaku, Tokyo, Japan), $45 \mathrm{mM}$ sodium acetate [pH 5.0], 0.01\% naphthol AS-MX phosphate (Sigma-Aldrich), $0.03 \%$ fast red violet LB salt (Sigma-Aldrich)) was added to each well and incubated for $10 \mathrm{~min}$ [19]. Cells were washed with water and observed through an optical microscope.

\subsection{ALP (Alkaline Phosphatase) Staining}

After the culture, cells were incubated with $100 \mu \mathrm{l}$ of $4 \%$ paraformaldehyde at $4^{\circ} \mathrm{C}$ for $1 \mathrm{~h}$. Each well was washed with distilled water, and then $100 \mu \mathrm{l}$ of ALP stain solution (100 mM Tris-HCl [pH 8.4], 0.01\% naphthol ASMX phosphate (Sigma-Aldrich), $0.06 \%$ fast blue BB salt (Sigma-Aldrich)) [20]. Cells were washed with distilled water and observed under an optical microscope.

\subsection{ALP Activity}

After the culture, cells were washed with PBS. The enzyme activity of ALP was measured by directly adding $100 \mu \mathrm{l} /$ well of ALP assay buffer $(0.6 \mathrm{M}$ diethanolamine (Sigma-Aldrich), $0.6 \mathrm{mM} \mathrm{MgCl}, 0.1 \%$ Triton X-100 (Sigma-Aldrich), and $30 \mathrm{mM}$ p-nitrophenylphosphate (Sigma-Aldrich)) to each well. After the incubation for 15 min at room temperature, the reaction was terminated by adding $50 \mu \mathrm{l} /$ well of $3 \mathrm{M} \mathrm{NaOH}$, and the absorbance was measured at $405 \mathrm{~nm}$ using microplate reader (SPECTRA MAX190, Molecular Devices, USA) [21]. The ALP activity was normalized to its protein concentration and represented as units per microgram of protein, with each unit of activity being defined as the amount of 
enzyme that produces $1 \mathrm{nmol}$ p-nitrophenol/min.

\subsection{Real-Time Quantitative PCR}

Total RNA was extracted with a standard acid-GTCphenol extraction method [22]. The cDNA from RAW264 cells was synthesized using M-MLV Reverse Transcriptase (Takara Bio, Otsu, Shiga, Japan). PCR was performed on a Gene Amp 5700 Sequence Detector (Applied Biosystems, Foster City, CA, USA) according to the manufacturer's instructions. All reactions were run in triplicate. After data collection, the mRNA copy number of a specific gene in total RNA was calculated with a standard curve generated with serially diluted plasmids containing PCR amplicon sequences, and normalized to the rodent total RNA with mouse GAPDH (glyceraldehyde 3-phosphate dehydrogenase) as an internal control. PCR was performed using the following primers: GAPDH, 5'-TGG TGA AGG TCG GTG TGA ACG G-3' (forward) and 5'-TGC CGT TGA ATT TGC CGT GAG T-3' (reverse); RANK, 5'-CAG TGT GCC TAC AGC ATG GGC T-3' (forward) and 5'-TCC AGT CAC GTT CCC AGA GGC A-3' (reverse); OSCAR, 5'-GCC TTC TGC CCC CTA TGT GCT A-3' (forward) and 5'-GCA GAG CTC CTG CTG TGC CAA T-3’ (reverse).

\subsection{PCR Analysis}

PCR was performed using the specific primers under the following conditions: for GAPDH primers $\left(95^{\circ} \mathrm{C}\right.$ for 5 min; 25 - 27 cycles of $95^{\circ} \mathrm{C}$ for $30 \mathrm{~s}, 55^{\circ} \mathrm{C}$ for $1 \mathrm{~min}$, $72^{\circ} \mathrm{C}$ for $1 \mathrm{~min} ; 72^{\circ} \mathrm{C}$ for $\left.7 \mathrm{~min}\right)$; for other primers $\left(95^{\circ} \mathrm{C}\right.$ for $5 \mathrm{~min}$; 20 - 40 cycles of $95^{\circ} \mathrm{C}$ for $30 \mathrm{~s}, 55^{\circ} \mathrm{C}$ for $1 \mathrm{~min}$, $72^{\circ} \mathrm{C}$ for $1 \mathrm{~min} ; 72^{\circ} \mathrm{C}$ for $7 \mathrm{~min}$ ).

\subsection{Western Blotting}

Cells were dissolved in a sample buffer ( $50 \mathrm{mM}$ Tris/HCl [pH 6.8], 2\% SDS, $6 \% \beta$-mercaptoethanol, 1 mM PMSF, 1 mM EDTA) with a supersonicator (Handy Sonic UR20P, TOMY SEIKO, Tokyo, Japan). SDS-PAGE was performed with $10 \mu \mathrm{g}$ of protein, and the separated proteins were transferred to a nitrocellulose membrane. The blotted membrane was soaked in 5\% BSA and incubated with primary antibody for phosphorylated Caspase-3, RANK and GAPDH (Cell Signaling Technology, Tokyo, Japan), and with a secondary antibody for HRP-conjugated anti-rabbit IgG (Cell Signaling Technology). Finally, each protein band was detected by chemiluminescence (Las1000, Fuji FILM, Minato, Tokyo, Japan).

\subsection{Cell Viability Detection by MTT Assay}

The viability of RAW264 cells for EGCG treatment was examined by MTT[3-(4,5-dimethyl thiazol-2-yl)-2,5dephenyl tetrazolium bromide]assay (Sigma-Aldrich).
Cells were cultured with EGCG $(0-100) \mu \mathrm{M}$ in the presence of RANKL $100 \mathrm{ng} / \mathrm{ml}$ for $24 \mathrm{~h}, 48 \mathrm{~h}$, or $72 \mathrm{~h}$. After $3 \mathrm{~h}$ culturing with MTT solution, reaction was terminated, and reaction product was dissolved in 0.04 $\mathrm{MHCl}$ in propan-2-ol. Absorbance was measured by microplate reader.

$$
\text { Viability }(\%)=\frac{\text { sample }(\text { OD570 }- \text { OD630) }}{\text { control }(\text { OD570 }- \text { OD630) }} \times 100,
$$

$\mathrm{n}=6$.

\subsection{Apoptosis Detection by Hoechst Staining}

The morphology of the nuclei for apoptotic changes of cells treated EGCG for $72 \mathrm{~h}$ was observed by Hoechst staining using an inverting fluorescence microscope (BZ-8000, KEYENCE, Osaka, Japan). Hoechst staining was conducted to observe the cells undergoing apoptosis. RAW264 cells were treated with (1 - 50) $\mu$ M EGCG for $72 \mathrm{~h}$ and apoptotic cells were stained by Hoechst method. Cells were collected by $0.25 \%$ trypsin, then fixed in $4 \%$ paraformaldehyde, washed twice with phosphate buffered saline (PBS) and permeabilized in Hoechst33258 (Sigma-Aldrich), and then directly observed under a fluorescence microscope.

\subsection{Statistical Analyses}

Results are expressed as mean \pm standard deviation. Comparisons between groups were made by analysis of variance and, when significant, were examined by Tukey's all-pairwise comparison test. Differences were considered significant when $P<0.05$.

\section{Results}

\subsection{EGCG Shows the Strongest Efficiency among Green Tea Catechins in Inhibiting Osteoclast-Like Development of RAW264 Cells}

We used RAW264 cells, a mouse macrophage-derived cell line that differentiates into osteoclast-like, multinucleated cells (MNCs) in the presence of RANKL [23]. Cells were treated with the following green tea polyphenoliccatechins applied at concentrations of either $10 \mu \mathrm{M}$ or $100 \mu \mathrm{M}$ : (-)-epigallocatechin-3-gallate (EGCG), (-)epigallocatechin (EGC), (-)-epicatechin-3-gallate (ECG), and (-)-epicatechin (EC), in the presence of $100 \mathrm{ng} / \mathrm{ml}$ RANKL. After culturing for $5 \mathrm{~d}$, the cells were stained by the TRAP method and the TRAP-positive MNCs were enumerated. The results shown in Figure 1 demonstrate that, at both $10 \mu \mathrm{M}$ and $100 \mu \mathrm{M}$ concentrations, EGCG had the most obvious effect in reducing the number of TRAP positive osteoclasts, by $19 \%$ and $96 \%$, re- 


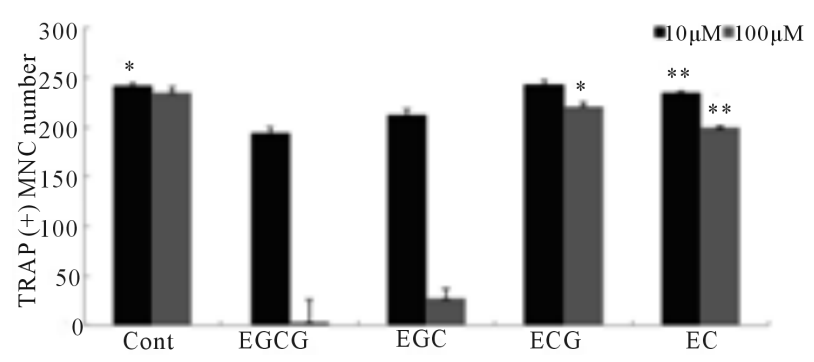

Figure 1. The efficiency of green tea catechins in osteoclastlike development of RAW264 cells. Cells were treated with EGCG, EGC, ECG and EC at both $10 \mu \mathrm{M}$ and $100 \mu \mathrm{M}$ in the presence of RANKL $(100 \mathrm{ng} / \mathrm{ml})$ for 5 days. TRAP positive MNCs were scored. Error bar shows S.E.M., based on three independent experiments $(n=6)$. Against a value of Cont, ${ }^{*} \boldsymbol{P}<0.05,{ }^{* *} P<0.01$.

spectively (n = 6, $P<0.01)$.

\subsection{EGCG Inhibits the Differentiation of RAW264 Cell Dose-Dependently}

RANKL-induced osteoclast differentiation in RAW264 cells was reduced in the presence of EGCG in a dosedependent manner. After EGCG (10, 25, 50, or $100 \mu \mathrm{M})$ treatment of RAW264 cells in the presence of $100 \mathrm{ng} / \mathrm{ml}$ RANKL, the ratio of MNCs were reduced to $79 \%, 68 \%$, $22 \%$, and $8 \%$ of MNCs in the control group (n $=6, P<$ 0.01) (Figures 2(a) and (b)).

To determine the stage of osteoclastogenesis which was affected by EGCG, we treated RANKL-induced RAW264 cells with EGCG $(10 \mu \mathrm{M})$ on different days, from day 0 to day 4 . On day 5, all treated cells were stained using the TRAP protocol. We found that EGCG initially reduced RANKL-induced TRAP-positive osteoclast numbers by $25 \%$ from day 0 to day 5 . After 1 day of stimulation, the number of TRAP-positive cells was reduced by $23 \%$ and after 2 days, it was reduced by $17 \%$. However, it did not significantly reduce the number of MNCs on day 3 (5\%) or on day 4 (4\%) after stimulation (Figure 2(c)).

\subsection{Effect of EGCG on the Differentiation of MC3T3-E1 Cell}

MC3T3-E1 cells, originally derived from mouse calvaria, were used to investigate the physiological role of EGCG on the differentiation of osteoblasts [24]. MC3T3-E1 cells were cultured in medium containing $10 \mu \mathrm{M}$ EGCG for $10 \mathrm{~d}$. The number of ALP-positive cells was decreased by stimulation with EGCG (Figure 3(a)). After treatment of cells with $10 \mu \mathrm{M}$ EGCG, ALP activity was reduced to about $61 \%$ of the control (Figure $3(\mathrm{~b})$ ), verifying that EGCG suppressed the differentiation of MC3T3-E1 cells.

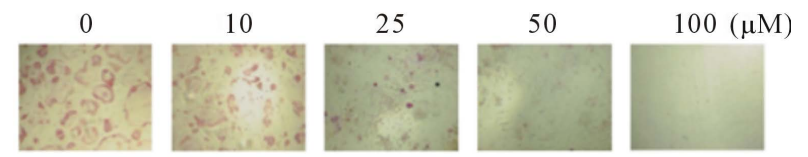

(a)

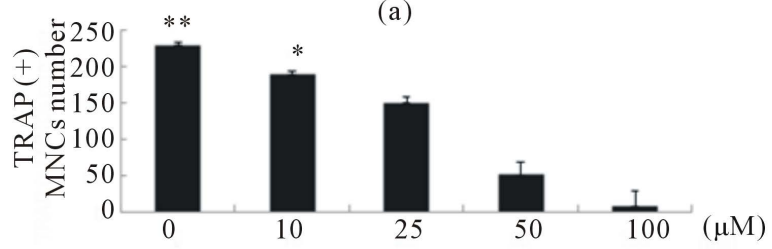

(b)

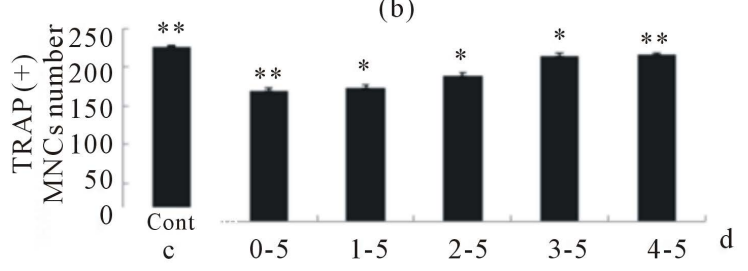

(c)

Figure 2. EGCG inhibits osteoclast differentiation of murine RAW264 cells dose-dependently. (a) RAW264 cells were cultured in $\alpha$-MEM with RANKL $(100 \mathrm{ng} / \mathrm{ml})$ for 5 days in the presence of EGCG, and stained by TRAP method; (b) The TRAP positive MNCs were scored. Error bar shows S.E.M., three experiments performed independently (n= 6). Against a value of $0 \mathrm{M},{ }^{*} P<0.05,{ }^{* *} P<0.01$; (c) RAW264 cells were treated with RANKL, and EGCG (10 $\mu M$ ) was added at the different time (day 0 - 4). The TRAP positive MNCs were scored. Error bar shows S.E.M., three experiments performed independently $(n=6)$. Against a value of Cont, ${ }^{*} P<0.05,{ }^{* *} P<0.01$.
0

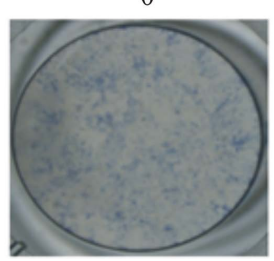

(a)

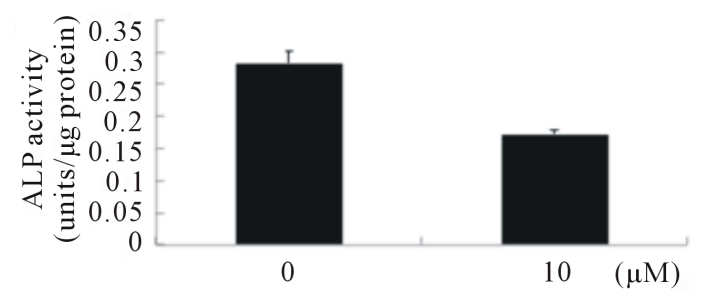

(b)

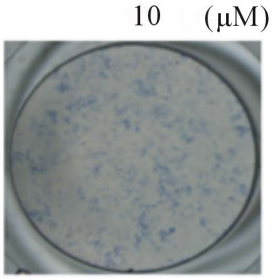

$0 \quad(\mu \mathrm{M})$
Figure 3. Effect of EGCG in osteoblast differentiation. MC3T3-E1 cells were used as a model for osteoblastic precursor cells. MC3T3-E1 cells were cultured with $10 \mu \mathrm{M}$ EGCG for 10 d. (a) After the culture, cells were fixed by $4 \%$ paraformaldyhede and stained by ALP method; (b) Cells were incubated with ALP assay buffer and ALP enzyme activity was measured. Error bar shows S.E.M., three experiments were performed independently $(n=6)$. 


\subsection{EGCG Inhibits Osteoclast Formation in Co-Culture Cells}

It is well known that osteoblasts induce the differentiation of osteoclasts through the production of RANKL and CSF-1 [25]. As shown by our previous data, EGCG has a suppressive effect on differentiation of precursor cells of osteoblasts but has little effect on differentiated osteoblasts [17]; therefore, the influence of EGCG on the differentiation of osteoclasts was analyzed by using a co-culture of differentiated osteoblasts and the precursor of osteoclasts. Osteoblasts collected from the calvaria of newborn mice and bone marrow cells collected from mouse tibiae and femurs were co-cultured on the same plate in the presence of $1,25(\mathrm{OH})_{2} \mathrm{D}_{3}$ to stimulate the differentiation of osteoclasts. Since the expression of TRAP is specific to osteoclasts, TRAP staining enabled definitive identification of osteoclasts in mixed cultures. The number of differentiated osteoclasts was decreased dose-dependently by different concentrations of EGCG treatment (Figure 4). These results confirmed that EGCG has a direct suppressive effect on osteoclast precursor cells.

\subsection{EGCG Affects the Expression of RANK in RAW264 Cells}

It is well known that the RANKL/RANK interaction plays an essential role in osteoclast formation in vivo [26] and targeted disruption of either RANKL or RANK results in severe osteopetrosis due to impaired formation of osteoclasts [5,27]. In addition, the mRNA expression level of RANKL is not changed in EGCG treated osteoblasts [17]. Therefore, we studied the direct influence of EGCG on the RANKL/RANK signal pathway by investigating the mRNA expression level of RANK, the receptor for RANKL. The results from RT-PCR and
0
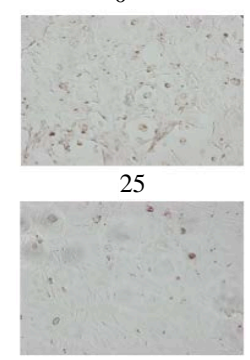

5

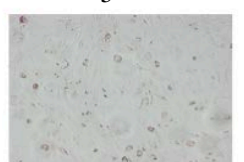

$50(\mu \mathrm{M})$

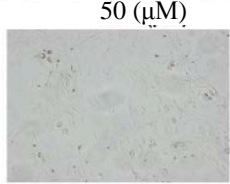

10

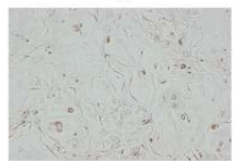

Figure 4. EGCG inhibits osteoclast formation in co-culture cells. Osteoblasts collected from the calvaria of mouse newborn and bone marrow cells collected from mouse tibia and femur were simultaneously cultured on the same plate for five days in the absence or presence of EGCG at various concentrations ( $(0 \mu \mathrm{M}, 5 \mu \mathrm{M}, 10 \mu \mathrm{M}, 25 \mu \mathrm{M}$, and $50 \mu \mathrm{M})$ under the stimulation of $10^{-8} \mu M 1,25(\mathrm{OH})_{2} D_{3}$. At the day 6 , cells were fixed and stained by TRAP method. real-time PCR show that after $3 \mathrm{~d}$ and $5 \mathrm{~d}$ of treatment with EGCG in the presence of RANKL, the expression level of RANK were reduced to $29 \%$ and $55 \%$ of control groups, respectively (Figures 5(A) and (B)).

Simultaneously, the mRNA level of osteoclast-associated receptor (OSCAR), a co-stimulator of RANK, was strongly reduced by EGCG treatment $(\mathrm{n}=3, P<0.01)$. Moreover, western blotting shows that EGCG visibly decreased the extent of RANK induction (Figure 5(C)). These results indicate that EGCG may directly influence the RANKL/RANK signal pathway by suppressing RANK expression.

\subsection{Effect of EGCG to the Expression of Osteoclastic Genes}

We examined the effects of EGCG on the expression of
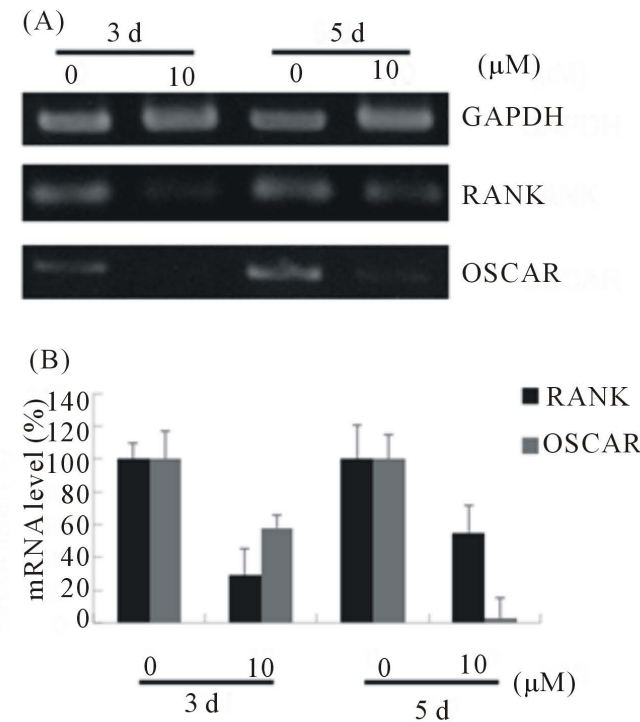

(C)

(a)

(b)
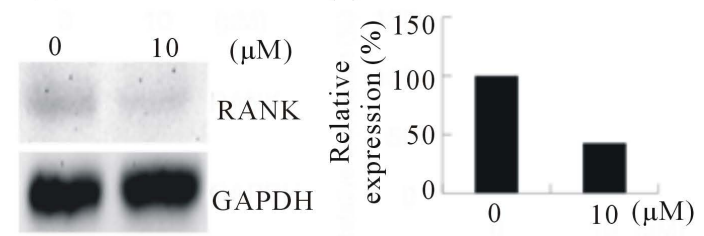

Figure 5. EGCG affects the expression of RANK in RAW264 cells. (A) RAW264 cells were treated with $10 \mu M$ EGCG in the presence of RANKL and RNA was extracted at day 3 and day 5 . The mRNA expression of RANK and OSCAR were determined by RT-PCR; (B) Real-time PCR was applied to obtain quantitative data of the mRNA expression of RANK and Oscar. Error bar shows S.E.M., three experiments performed independently $(n=3)$; (C) Cells were cultured with EGCG $(0 \mu \mathrm{M}, 10 \mu \mathrm{M})$ in the presence of RANKL for $3 \mathrm{~d}$ and subjected to western blot analysis (a), and the histogram represents the level of relative expression (\%) compared with that of control (b). 
mRNAs for osteoclast-specific genes by RT-PCR. RNA was extracted from RAW264 cells treated with or without $10 \mu \mathrm{M}$ EGCG and $100 \mathrm{ng} / \mathrm{ml}$ RANKL, at day 3 and day 5 of culture. As shown in Figure 6, EGCG did not influence mRNA levels of TRAP [28] or Cathepsin K [3], while the mRNA levels of other osteoclast specific genes such as calcitonin receptor (CtR) [7] and matrix metalloproteinase 9 (MMP9) [29] were decreased. In addition, the nuclear factor of activated T cell c1 (NFATc1), a key transcription factor induced by RANKL was reduced by EGCG treatment. These results indicated that EGCG has an inhibitory effect to osteoclastogenesis by specifically regulating some osteoclastic genes in RAW264 cells.

\subsection{EGCG Influenced the Apoptosis-Related Genes Expression in Osteoclast Differentiation}

FOXO3a is well known for inducing cell apoptosis [30], and apoptosis of osteoclasts is regulated by the Caspase3-Bim axis [15]. Therefore, using RT-PCR, we investigated the effect of EGCG treatment on the mRNA level of gene expression of FOXO3a, Bim, andSIRT1, which regulates the ability of FOXO3a in inducing apoptosis. As shown in Figure 7(A), both FOXO3a and Bim were increased, while SIRT1 was decreased by EGCG. In addition, western blotting represented that Caspase-3 protein level increased by EGCG treatment (Figure 7(B)). These results indicate that EGCG induced cell apoptosis in osteoclast differentiation.

An MTT assay was performed to investigate the cell viability after EGCG treatment. RAW264 cells were treated with different concentrations of EGCG in the presence of $100 \mathrm{ng} / \mathrm{ml}$ RANKL for $24 \mathrm{~h}, 48 \mathrm{~h}$, or $72 \mathrm{~h}$. No obvious reduction in cell viability was apparent in cells cultured with up to $50 \mu \mathrm{M}$ EGCG, although treat-

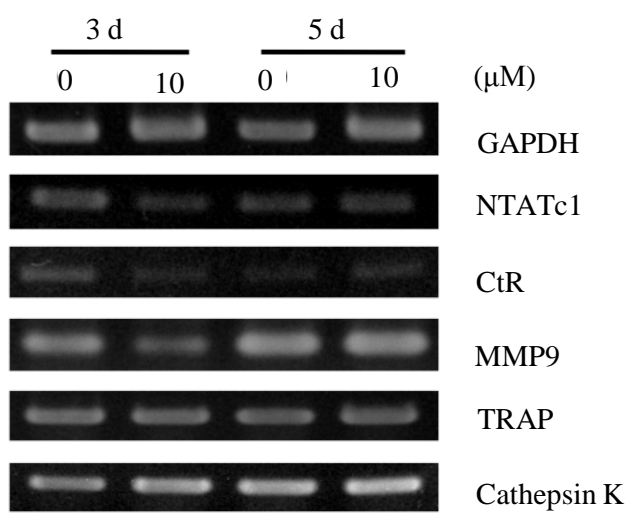

Figure 6. Effect of EGCG to the expression of osteoclastic genes.RAW264 cells were treated with $10 \mu \mathrm{M}$ EGCG in the presence of RANKL, and RNA was extracted at day 3 and day 5. RT-PCR was performed with specific primers for each genes.

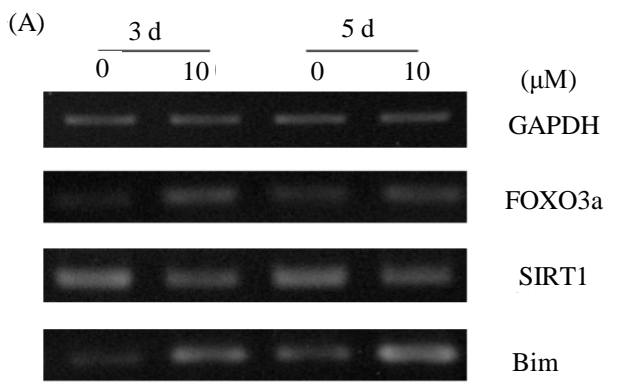

(B)
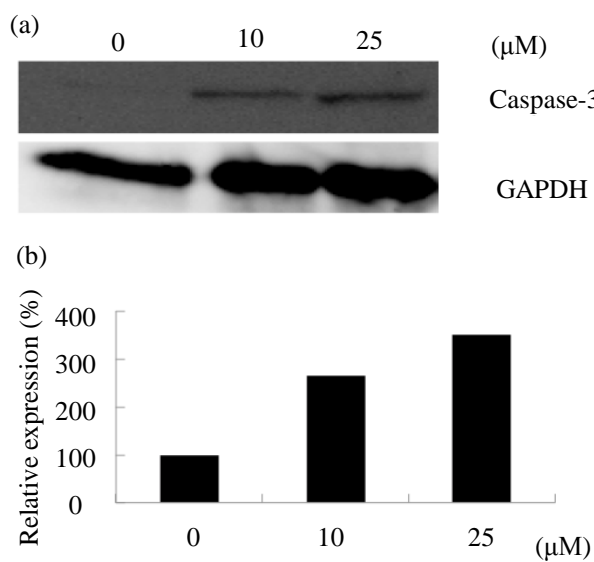

Figure 7. EGCG influenced the apoptosis-related genes expression and activation of caspase-3. (A) RAW264 cells were cultured with EGCG $(10 \mu \mathrm{M})$ in the presence of RANKL for $5 \mathrm{~d}$. At the day 3 and day 5, RNA was extracted and RT-PCR was performed; (B) RAW264 cells were cultured with EGCG $(0 \mu \mathrm{M}, 10 \mu \mathrm{M}, 25 \mu \mathrm{M})$ in the presence of RANKL for $3 \mathrm{~d}$ and subjected to Western blot analysis (a). The histogram represents the levels of relative expression (\%) compared with that of control (b).

ment with $100 \mu \mathrm{M}$ EGCG reduced the cell viability considerably (Figure 8(a)). For further confirmation, cells were stained with Hoechst33258 to observe the morphological characteristics of apoptotic cells. Hoechst staining indicated that Hoechst-positive cells were increased in RAW264 cells in response to EGCG in a dose-dependent manner as compared to the control group (Figure 8(b)).

\section{Discussion}

Regular tea drinkers are reported to be at reduced risk of hip fractures and to have a higher bone mineral density (BMD) [31,32]. It has been reported that some green tea polyphenols physiologically regulate bone metabolism [33].

In this study, first, we compared the efficiency of the inhibitory effect of EGCG with that of other green tea catechins, namely EGC, ECG, and EC. The study was performed with RANKL-induced osteoclastogenesis in RAW264 cells, a homogeneous clonal population of mu- 
(a)

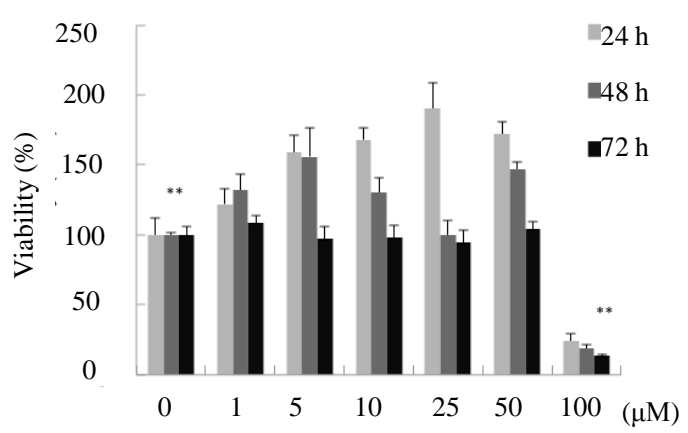

(b)
0

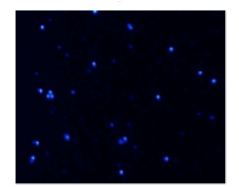

25

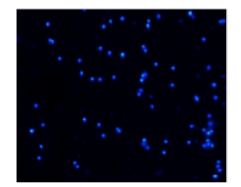

5

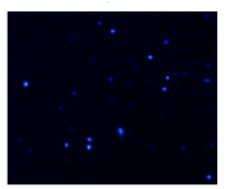

$50(\mu \mathrm{M})$

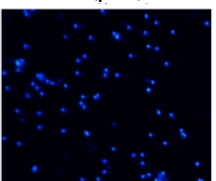

10

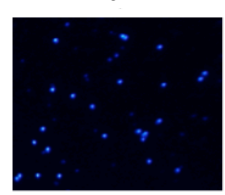

Figure 8. Confirmation of the apoptosis-inducing effect of EGCG in RAW264 cells. (a) RAW264 cells were cultured with EGCG $(0-100 \mu \mathrm{M})$ in the presence of RANKL for 24 h, $48 \mathrm{~h}$, or $72 \mathrm{~h}$. Cells were cultured with MTT solution for another $3 \mathrm{~h}$. Absorbance was measured by microreader, and the viability was calculated in the manner: viability (\%) $=$ sample (OD570-OD630)/control (OD570-OD630) $\times \mathbf{1 0 0}$. Error bar shows S.E.M., three experiments performed independently $(\mathrm{n}=6)$. Against a value of $0 \mathrm{M},{ }^{* *} \mathrm{P}<0.01$; (b) RAW264 cells were cultured with EGCG $(0$ - $50 \mu \mathrm{M})$ in the presence of RANKL for $72 \mathrm{~h}$ and fixed by $4 \%$ paraformaldehyde. Cells were stained by Hoechst 33258 solution and photographed by a fluorescence microscope.

rine monocytic cells. RAW264 cells do not include any osteoblasts, or bone marrow stromal cells that produce cytokines such as M-CSF and OPG [34], which allow us to rule out cell and cytokine factors and focus on RANKL/RANK signaling in preosteoclastogenesis. As the result shows, among the polyphenols found in green tea, EGCG was the most effective catechin in inhibiting osteoclast differentiation by leading to the lowest number of MNCs at both low and high concentrations. Osteoclast differentiation decreased in a dose-dependent manner in response to treatment with various concentrations of EGCG for 5 d. However, this inhibition mainly occurred in the initial stage of osteoclastogenesis when cell fusion and multinucleated cell formation occurs.

Furthermore, ALP staining and ALP activity showed that EGCG inhibited the differentiation of murine osteoblastic MC3T3-E1 cells. RT-PCR analysis of RANKL in osteoblasts revealed that EGCG did not change the mRNA expression level of RANKL [17]. Because RANKL produced by osteoblasts results in the differentiation of osteoclasts, it is possible that apart from the direct inhibitory effect on osteoclastogenesis, EGCG will also influence osteoclastogenesis indirectly by affecting the differentiation of osteoblast precursor cells in vivo. Therefore, the indirect effect of EGCG by inhibition of the differentiation of osteoblasts was excluded by applying a co-culture system of calvaria-derived osteoblasts and bone marrow cells from a 6-week-old male mouse was used to obtain physiological proof of the ability of EGCG to induce osteoclastogenesis. The results showed the effect of EGCG in physiological condition.

Next, we provided an insight into the mode of action of EGCG on osteoclast differentiation and showed that EGCG interferes with RANKL signaling. This cytokine is indispensable for triggering the full osteoclast differentiation program [29]. First, we showed that, in the presence of EGCG, the mRNA levels of theosteoclastic genes, CtR and MMP9 were downregulated, but there was no obvious effect on the expression of TRAP and Cathepsin K. Secondly, we showed that EGCG prevents the induction of NFATc1, a downstream transcription factor induced by RANKL, which was reported to be indispensable for differentiation of monocytes into osteoclasts [11]. Furthermore, both RANK and OSCAR, a key osteoclast-specific gene costimulation molecule, which is involved in the induction of NFATc1 by RANKL, were found to be downregulated. Because NFATc1 is a key transcription factor that regulates osteoclast-specific genes, CtR, TRAP, Cathepsin K, and even OSCAR $[7,8]$, one may speculate that inhibited induction of NFATc1 contributes to the inhibition of osteoclastogenesis. However, the reduced expression levels of RANK and OSCAR drew our attention to the possibility that downregulated RANKL/RANK signaling pathway by EGCG results in the impaired NFATc1 stimulation. Of course, additional targets of EGCG cannot be excluded. In addition to its action on RANKL signaling, EGCG may also affect cellular changes occurring during the terminal differentiation of osteoclasts. Indeed, we found that the formation of osteoclasts was also inhibited when EGCG was added 3 days after RANKL stimulation, at a time point where NFATc1 is already activated [35]. Taken together, our findings show that EGCG can inhibit RANKL-induced osteoclastogenesis at several critical steps, including the RANKL/RANK signaling pathway itself.

On the other hand, SIRT1 has been known to inhibit FOXO3a's ability to induce cell death [12]. Also, Bim has described as an activator in Caspase-3-Bim axis in regulating apoptosis has been reported to play an important role in regulating the apoptosis of osteoclasts $[14,15]$. 
Therefore, we examined the mRNA expression levels of SIRT1, FOXO3a and Bim on RANKL-induced osteoclast differentiation after EGCG treatment using RT-PCR. Upregulated FOXO3a, Bim, and reduced SIRT1 indicated that the apoptosis of RAW264 cells might be enhanced by EGCG treatment. EGCG-induced apoptosis through downstream activation of caspase is well characterized in various cancer cells. However, it is reported thatcatechin, a component of green tea, causes caspaseindependent necrosis-like cell death in chronic myelogenous leukemia [36]. Whether caspase activation was involved in the death of murine osteoclasts by EGCG remains to be clarified. Western blotting results showed increased Caspase-3 activation. Furthermore, the apoptosis-inducing effect of EGCG on osteoclast precursor cells was confirmed by Hoechst staining, while the MTT assay revealed that up to $50 \mu \mathrm{M}$, EGCG treatment had no effect on cell viability, which might to be explained as the result of increased mitochondrial activity in RAW264 cells due to treatment with EGCG. These results suggest that the pro-apoptotic function of Caspase-3-Bim might play an important role in EGCG-induced apoptosis in RAW264 cells.

Thus far, it has been reported that the concentration of EGCG reaches to approximately $10 \mu \mathrm{M}$ in blood by oral administration of high dose of EGCG [37]. Through this whole study, we mainly used $10 \mu$ M EGCG, a concentration that is close to that found in vivo. Therefore, EGCG should one day be found applicable in the treatment of bone lesions in nonmalignant diseases such as osteoporosis.

\section{Conclusion}

This in vitro study revealed that EGCG suppressed osteoclast differentiation at an early stage of osteoclastogenesis in cultured RAW264 cells through the down regulation of RANK and OSCAR. Furthermore, EGCG simultaneously increased FOXO3a-related apoptosis in EGCG-treated RAW264 cells via a caspase-dependent pathway. These results suggest that EGCG is potentially beneficial in the protection and treatment of bone lesions in the future.

\section{Acknowledgements}

This work was supported in part by Grants-in-Aid for Scientific Research from the Ministry of Education, Science, Sports, and Culture of Japan. We wish to thank Mitsui Norin Co. Ltd. for providing catechin compounds.

\section{REFERENCES}

[1] C. Menaa, N. Kurihara and G. D. Roodman, “CFU-GM
Derived Cells Form Osteoclasts at a Very High Efficiency," Biochemical and Biophysical Research Communications, Vol. 267, No. 3, 2000, pp. 943-946.

http://dx.doi.org/10.1006/bbrc.1999.2042

[2] M. Zaidi, "Skeletal Remodeling in Health and Disease," Nature Medicine, Vol. 13, No. 7, 2007, pp. 791-801. http://dx.doi.org/10.1038/nm1593

[3] M. Yavropoulou and J. G. Yovos, "OsteoclastogenesisCurrent Knowledge and Future Perspectives,” The Journal of Musculoskeletal and Neuronal Interactions, Vol. 8, No. 3, 2008, pp. 204-216.

[4] O. H. Kwon, C. K. Lee, Y. I. Lee, S. G. Paik and H. J. Lee, "The Hematopoietic Transcription Factor PU.1 Regulates RANK Gene Expression in Myeloid Progenitors,” Biochemical and Biophysical Research Communications, Vol. 335, No. 2, 2005, pp. 437-446. http://dx.doi.org/10.1016/j.bbrc.2005.07.092

[5] W. C. Dougall, M. Glaccum, K. Charrier, K. Roharbach, T. De Smedt, E. Daro, J. Smith, M. E. Tometsko, C. R. Maliszewski, A. Armstrong, V. Shen, S. Bain, D. Cosman, D. Anderson, P. J. Morrissey, J. J. Peschon and J. Schuh, "RANK Is Essential for Osteoclast and Lymph Node Development," Genes and Development, Vol. 13, 1999, pp. 2412-2424. http://dx.doi.org/10.1101/gad.13.18.2412

[6] H. Takayanagi, "Induction and Activation of the Transcription Factor NFATc1 (NFAT2) Integrate RANKL Signaling for Terminal Differentiation of Osteoclasts," Developmental Cell, Vol. 3, No. 6, 2002, pp. 889-901. http://dx.doi.org/10.1016/S1534-5807(02)00369-6

[7] M. Matsumoto, M. Kogawa, S. Wada, H. Takayanagi, M. Tsujimoto, S. Katayama, K. Hisatake and Y. Nogi, "Essential Role of p38 Mitogen-Activated Protein Kinase in Cathepsin K Gene Expression during Osteoclastogenes Is through Association of NFATc1 and PU.1," Journal of Biological Chemistry, Vol. 279, No. 44, 2004, pp. 4596945979. http://dx.doi.org/10.1074/jbc.M408795200

[8] Y. Kim, K. Sato, M. Asagiri, I. Morita, K. Soma and H. Takayanagi, "Contribution of NFATc1 to the Transcriptional Control of Immuno Receptor OSCAR But Not TREM-2 during Osteoclastogenesis,” Journal of Biological Chemistry, Vol. 280, No. 38, 2005, pp. 32905-32913. http://dx.doi.org/10.1074/jbc.M505820200

[9] N. Kim, M. Takami and J. Rho, “A Novel Member of the Leukocyte Receptor Complex Regulates Osteoclast Differentiation,” Journal of Experimental Medicine, Vol. 195, No. 2, 2002, pp. 201-209.

[10] T. Koga, "Costimulatory Signals Mediated by the ITAM Motif Cooperate with RANKL for Bone Homeostasis," Nature, Vol. 428, No. 6984, 2004, pp. 758-763. http://dx.doi.org/10.1038/nature02444

[11] H. Takayanagi, "Osteoimmunology: Shared Mechanisms and Crosstalk between the Immune and Bone Systems," Nature Reviews Immunology, Vol. 7, No. 4, 2007, pp. 292-304. http://dx.doi.org/10.1038/nri2062

[12] A. Brunet, L. B. Sweeney, J. F. Sturgill, K. F. Chua, P. L. Greer, Y. Lin, H. Tran, S. E. Ross, R. Mostoslavsky, H. Y. Cohen, L. S. Hu, H. L. Cheng, M. P. Jedrychowski, S. P. Gygi, D. A. Sinclair, F. W. Alt and M. E. Greenberg, 
"Stress-Dependent Regulation of FOXO Transcription Factors by the SIRT1 Deacetylase," Science, Vol. 303, No. 5666, 2004, pp. 2011-2015.

http://dx.doi.org/10.1126/science.1094637

[13] G. Dewson, T. Kratina, H. W. Sim, H. Puthalakath, J. M. Adams, P. M. Colman and R. M. Kluck, "To Trigger Apoptosis, Bak Exposes Its BH3 Domain and Homodimerizes via BH3: Groove Interactions,” Molecular Cell, Vol. 30, No. 3, 2008, pp. 369-380. http://dx.doi.org/10.1016/j.molcel.2008.04.005

[14] E. Gavathiotis, M. Suzuki, M. L. Davis, K. Pitter, G. H. Bird, S. G. Katz, H. C. Tu, H. Kim, E. H. Cheng, N. Tjandra and L. D. Walensky, "BAX Activation Is Initiated at a Novel Interaction Site,” Nature, Vol. 455, No. 7216, 2008, pp. 1076-1081. http://dx.doi.org/10.1038/nature07396

[15] S. Tanaka, H. Wakeyama, T. Akiyama, K. Takahashi, H. Amano, K. I. Nakayama and K. Nakamura, "Regulation of Osteoclast Apoptosis by bcl-2 Family Protein Bim Andcaspase-3," Advances in Experimental Medicine and Biology, Vol. 658, 2010, pp. 111-116.

[16] H. J. Fujiki, "Two Stages of Cancer Prevention with Green Tea,” Journal of Cancer Research and Clinical Oncology, Vol. 125, No. 11, 1999, pp. 589-597. http://dx.doi.org/10.1007/s004320050321

[17] M. Kamon, R. Zhao and K. Sakamoto, "Green Tea Polyphenol (-)-Epigallocatechingallate Suppressed the Differentiation of Murine Osteoblastic MC3T3-E1 Cell,” Cell Biology International, Vol. 34, 2010, pp. 109-116.

[18] H. Takahashi, Y. Akatsu, N. Udagawa, T. Sasaki, A. Ymaguchi and J. M. Moseley, "Osteoblastic Cells Are Involved in Osteoclast Formation,” Endocrinology, Vol. 123, No. 5, 1988, pp. 2600-2602.

http://dx.doi.org/10.1210/endo-123-5-2600

[19] M. Matsumoto, T. Sudo, M. Maruyama, H. Osada and M. Tsujimoto, “Activation of p38 Mitogen-Activated Protein kinase Is Crucial in Osteoclastogenesis Induced by Tumor Necrosis Factor," FEBBS Letter, Vol. 486, No. 1, 2000, pp. 23-28. http://dx.doi.org/10.1016/S0014-5793(00)02231-6

[20] J. K. Chang, Y. L. Hsu, I. C. Teng and P. L. Kuo, "Piceatannol Stimulates Osteoblast Differentiation that May Be Mediated by Increased Bone Morphogenetic Protein-2 Production,” European Journal of Pharmacology, Vol. 551, No. 1-3, 2006, pp. 1-9. http://dx.doi.org/10.1016/j.ejphar.2006.08.073

[21] K. Kodaria, M. Imada, M. Goto, A. Tomoyasu, T. Fukuda and R. Kamijo, "Purification and Identification of a BMPLike Factor from Bovine Serum,” Biochemical and Biophysical Research Communications, Vol. 345, No. 3, 2006, pp. 1224-1231. http://dx.doi.org/10.1016/j.bbrc.2006.05.045

[22] P. Chomczynski and N. Sacchi, "Single-Step Method of RNA Isolationby Acid Guanidiniumthiocyanate-phenolChloroform Extraction," Analytical Biochemistry, Vol. 162, 1987, pp. 156-159. http://dx.doi.org/10.1016/0003-2697(87)90021-2

[23] N. Ishida, K. Hayashi, M. Hoshijima, T. Ogawa, S. Koga and Y. Miyatake, "Large Scale Gene Expression Analysis of Osteoclastogenesis in Vitro and Elucidation of NFAT2 as a Key Regulator,” Journal of Biological Chemistry, Vol. 277, No. 43, 2002, pp. 41147-41156. http://dx.doi.org/10.1074/jbc.M205063200

[24] H. Kodama, Y. Amagai and S. Sudo, "Establishment of a Clonal Osteogenic Cell Line from Newborn Mouse Calvaria,” Japanese Journal of Oral Biology, Vol. 23, 1981, pp. 899-901.

http://dx.doi.org/10.2330/joralbiosci1965.23.899

[25] T. Katagiri and N. Takahashi, "Regulatory Mechanisms of Osteoblast and Osteoclast Differentiation," Oral Diseases, Vol. 8, No. 3, 2002, pp. 147-159.

http://dx.doi.org/10.1034/j.1601-0825.2002.01829.x

[26] W. J. Boyle, W. S. Simonet and D. L. Lacey, “Osteoclast Differentiation and Activation," Nature, Vol. 423, No, 6937, 2003, pp. 337-342. http://dx.doi.org/10.1038/nature01658

[27] Y. Y. Kong, H. Yshida, I. Sarosi, H. L. Tan, E. Timms, C. Capparelli, S. Morony, A. J. Oliveira-dos-Santos, G. Van, A. Itie, W. Khoo, A. Wakeham, C. R. Dunstan, D. L. Lacey, T. W. Mak, W. J. Boyle and J. M. Penninger, "OPGL Is a Key Regulator of Osteoclastogenesis, Lymphocyte Development and Lymph-Node Organogenesis,” Nature, Vol. 397, No. 6717, 1999, pp. 315-323. http://dx.doi.org/10.1038/16852

[28] D. J. Eric, P. Lan, J. B. J. Charles, E. Kelly, E. C. Ann, J. W. Jennifer, P. Anna, G. Rajaram and M. Kim, "Bone Morphogenic Protein 2 Directly Enhances Differentiation of Murine Osteoclast Precursors," Journal of Cellular Biochemistry, Vol. 109, No. 4, 2010, pp. 672-682.

[29] I. Song, J. H. Kim, K. Kim, H. M. Jin, B. U. Youn and N. Kim, "Regulatory Mechanism of NFATc1 in RANKLInduced Osteoclast Activation,” FEBS Letter, Vol. 583, No. 14, 2009, pp. 2435-2440. http://dx.doi.org/10.1016/j.febslet.2009.06.047

[30] Y. C. Shang, Z. Z. Chong, J. Hou and K. Maiese, "Foxo3a Governs Early Microglial Proliferation and Employs Mitochondrial Depolarization with Caspase 3, 8, and 9 Cleavage during Oxidant Induced Apoptosis," Current Neurovascular Research, Vol. 6, No. 4, 2009, pp. 223238. http://dx.doi.org/10.2174/156720209789630302

[31] O. Johnell, B. Gullberg, J. A. Kanis, E. Allander, L. Elffors, J. Dequeker, G. Dilsen, C. Gennari, V. A. Lopes and G. Lyritis, "Risk Factors for Hip Fracture in European Women: The MEDOS Study,” Journal of Bone and Mineral Research, Vol. 10, No. 11, 1995, pp. 1802-1815. http://dx.doi.org/10.1002/jbmr.5650101125

[32] V. M. Hegarty, H. M. May and K. T. Khaw, “Tea Drinking and Bone Mineral Density in Older Women,” The American Journal of Clinical Nutrition, Vol. 71, No. 4, 2000, pp. 1003-1007.

[33] J. H. Yun, C. S. Kim, K. S. Cho, J. K. Chai, C. K. Kim and S. H. Choi, "(-)-Epigallocatechin Gallate Induces Apoptosis, via Caspase Activation, in Osteoclasts Differentiated from RAW246.7 Cells,” Journal of Periodontal Research, Vol. 42, 2007, pp. 212-218. http://dx.doi.org/10.1111/j.1600-0765.2006.00935.x

[34] A. C. Bharti, Y. Takada and B. B. Aggarwal, "Curcumin 
(Diferuloylmethane) Inhibits Receptor Activator of NFkappa B Ligand-Induced NF-Kappa B Activation in Osteoclast Precursors and Suppresses Osteoclastogenesis,” Journal of Immunology, Vol. 172, No. 10, 2004, pp. 59405947.

[35] P. Boissy, T. L. Andersen, B. M. Abdallah, M. Kassem, T. Plesner and J. M. Delaisse, "Resveratrol Inhibits Myeloma Cells Growth, Prevents Osteoclast Formation, and Promotes Osteoblast Differentiation,” Cancer Research, Vol. 65, No. 21, 2005, pp. 9943-9952. http://dx.doi.org/10.1158/0008-5472.CAN-05-0651

[36] R. Iwasaki, K. Ito, T. Ishida, M. Hamanoue, S. Adachi, T.
Watanabe and Y. Sato, “Catechin, Green Tea Component, Causes Caspase-Independent Necrosis-Like Cell Death in Chronic Myelogenous Leukemia,” Cancer Science, Vol. 100, No. 2, 2009, pp. 349-356.

http://dx.doi.org/10.1111/j.1349-7006.2008.01046.x

[37] U. Ullmann, J. Haller, J. P. Decourt, N. Girault, J. Girault and A. S. Richard-Caudron, "A Single Ascending Dose Study of Epigallocatechingallate in Healthy Volunteers," Journal of International Medical Research, Vol. 31, No. 2, 2003, pp. 88-101. http://dx.doi.org/10.1177/147323000303100205 